\title{
Estroos RBEF
}

\section{Fonologia e vocabulário na percepção de educadoras sobre comunicação de pré-escolares}

Rita de Cássia Alves Limissuri

Débora Maria Befi-Lopes

\section{Resumo}

Entre os subsistemas da linguagem, a fonologia e o léxico são aqueles que podem ser observados por qualquer pessoa do convívio da criança logo no início do desenvolvimento. No entanto, sabe-se que há diferentes maneiras de se considerar a linguagem infantil e o que parece ser uma alteração para um, pode ser considerado normal para outro. A pesquisa verifica a influência da fonologia e do vocabulário na percepção de educadoras sobre a comunicação de pré-escolares e contou com a participação de sete educadoras e 123 crianças. A avaliadora perguntou a cada uma das educadoras quais crianças de sua sala elas julgavam ter alguma dificuldade de comunicação e por quê. Em seguida, foram aplicadas provas de fonologia e de vocabulário em todas as crianças da sala (as citadas e as não citadas pelas educadoras). Os resultados indicaram que, para cada faixa etária, a influência da fonologia e do vocabulário foi percebida pelas educadoras de maneira diferente. Uma relação mais próxima entre fonoaudiologia e educação se faz importante, uma vez que se nota a necessidade de esclarecer o que é normal e o que não é mais aceito, para cada idade, no que se refere ao desenvolvimento da fonologia e do vocabulário.

Palavras-chave: pré-escolares; educadoras; fonologia; vocabulário. 


\section{Abstract \\ Preschooler's communication: phonology and vocabulary from the point of view of teachers}

Among the language subsystems, the phonology and the lexicon are the ones that can be observed by anybody of the child's close relationship from the very beginning of the child's development. However, we know that there are different ways to considerer the child language. After all, what for somebody seems a kind of disturbance; it can be considered normal by other person. This research intends to verify the influence of the phonology and vocabulary from the educators' grasp about the preschoolers' communication. It counted on the participation of 7 educators and 123 children. The evaluator asked each educator the following question: which children in your classroom do you judge to have some communication difficulty? And why? Soon afterwards, the phonology test and vocabulary test were applied to all children of the classroom (those mentioned and not mentioned by the educators). The results indicated that, for each age group, the influence of the phonology and vocabulary in the educators' perception was understood in different ways. Thus a closer relationship between phonology and Education is important once we noticed the necessity to explain what is normal and what is not acceptable any more for each age, regarding the development of the phonology and vocabulary.

Keywords: preschoolers; educators; phonology; vocabulary.

\section{Linguagem infantil, educadores e fonoaudiologia: uma breve revisão da história}

A intersecção que envolve linguagem, ambiente de educação e fonoaudiologia é histórica. É histórica, também, a suscetibilidade da linguagem humana a diferentes definições, pontos de vista e interpretações. A esse respeito, Lahey (1990) ressaltou que o conhecimento que as crianças têm sobre o sistema linguístico ou sobre linguagem comunicativa não é algo diretamente observável.

Mesmo havendo teorias clássicas sobre o desenvolvimento de linguagem, podemos notar que, ao longo do tempo, ocorreram significativas mudanças a respeito do que se acredita ser um "distúrbio de linguagem". Em nosso País, medidas governamentais acabaram por gerar uma intensa reflexão acerca desse assunto, e uma breve retrospectiva nos permitirá compreender melhor a relação entre 
educador, linguagem infantil e fonoaudiólogo estabelecida em nossa pesquisa.

Berberian (2000) explicou que, no final do século 19, já havia se iniciado uma tentativa de normatizar a língua portuguesa. Na década de 20, os governantes brasileiros encontravam-se bastante preocupados com aquilo que eles chamavam de patologia social, ou seja, os hábitos, os costumes e, principalmente, as línguas diferentes (consideradas defeitos da palavra), vindos juntamente com os imigrantes que chegavam. Diversos especialistas receberam, então, a função de salvar o País dessa suposta patologia.

Segundo a autora, médicos, higienistas, educadores, engenheiros e agentes públicos elegeram a escola como o melhor lugar para o tratamento desses problemas sociais. Houve, assim, uma campanha de nacionalização e regeneração do ensino.

Na década de 30, os agentes sociais já falavam em distúrbios de linguagem, porém se referiam às variações dialetais expressas na fala dos imigrantes e, também, às contidas na fala dos próprios brasileiros, que vinham de diferentes regiões do País para os centros urbanos. Ainda nessa década, lembrou a autora, foi realizada uma pesquisa com mais de 4.000 crianças de 3 a 12 anos - a fim de se eleger a mais perfeita manifestação da língua para instituí-la em todo o País - e a conclusão foi de que os distúrbios manifestados pelas crianças estavam relacionados ao contato com outros idiomas, por meio dos pais. Dessa forma, os pais foram considerados como a maior causa dos distúrbios observados. A família deveria, assim, deixar de ser responsável pelo ensino da língua aos seus filhos e, mais uma vez, a escola foi incumbida dessa função.

A educação da fala foi incluída no currículo escolar e, em vários cursos de formação de professores, foi introduzida a matéria metodologia da linguagem. Aos poucos, os professores, junto aos outros profissionais que receberam a função de limpar a língua, ou seja, de fazer com que todos falassem da mesma forma, foram especializando-se e passando a ser terapeutas, nascendo a fonoaudiologia, conforme contou Berberian (2000).

\section{As opiniões não são iguais: as pessoas também não são}

Parece-nos um equívoco julgar que os profissionais estabelecem entre si uma comunicação plena e clara em todos os momentos. O que salta aos olhos (ou aos ouvidos) de alguém pode divergir da interpretação feita pelo outro. Befi-Lopes (2003) apontou que o processo de identificação da alteração é motivo de controvérsia entre diversos profissionais, em razão de uma falta de exatidão no estabelecimento do que vem a ser linguagem (e desordem de linguagem) e, também, em consequência das variações intersujeitos. Sobre esse assunto, Eisenson (1986) reforçou que nenhum ser humano, mesmo sendo da mesma faixa etária, é igual ao outro, existindo uma variação entre os sujeitos que pode ser considerada normal.

Para Martin e Miller (1996), diferentes valores são atribuídos ao uso da interação verbal, porém ressaltaram que é importante ter claro o que 
é uma variação normal e o que é realmente um problema. As autoras concordaram que há diferenças na maneira de se compreender e falar sobre fala e linguagem. Essas diferenças vão depender da área em que o profissional se encaixa, ou seja, profissionais da linguística, da psicologia e da educação poderão ter opiniões divergentes - o que gera controvérsias, também, ao tentar-se quantificar e categorizar dificuldades apresentadas pelas crianças. Elas ainda citaram os professores como profissionais que têm consciência das variações de desenvolvimento existentes dentro da própria normalidade e que são capazes, por experiência, de identificar quando uma criança é muito diferente das outras e quando essa diferença poderá interferir em sua capacidade de aprender.

\section{Vocabulário e fonologia: por que eles?}

A primeira razão pela qual esses dois itens foram escolhidos para nortearem nossa pesquisa é o fato de que eles são bastante precoces no desenvolvimento e que, segundo Befi-Lopes e Galea (2000), entre todos os componentes da linguagem (sintaxe, morfologia, semântica, fonologia e pragmática), a fonologia e o vocabulário são aqueles que primeiro podem ser observados por qualquer pessoa do convívio da criança, logo que ela inicie o processo de fala.

A segunda razão é a reconhecida importância dessas duas habilidades em etapas posteriores do desenvolvimento. Em 1978, Cunha e Castro ressaltaram a importância de uma linguagem verbal adequada para o início do processo de alfabetização e, futuramente, para a comunicação escrita e a fixação de conceitos. As autoras mencionaram que o enriquecimento do vocabulário é indispensável a uma forma de expressão mais eficiente e que a pronunciação correta é importante tanto para possibilitar a alfabetização quanto para um bom desempenho social da linguagem.

Ainda nos dias atuais, a fonologia é fortemente associada ao desenvolvimento escolar, e o transtorno da fonologia, aos problemas relacionados à leitura e à escrita, entre eles, a dislexia (Stackhouse, 2004; Snowling, 2004).

Sobre o vocabulário, Stahl (2003) afirmou que as palavras que conhecemos nos ajudam a compreender o mundo que nos cerca, acrescentando que o conhecimento de vocabulário é, também, correlacionado à compreensão de leitura e afeta todos os aspectos de conhecimento da língua. Além disso, o início tardio da aquisição do vocabulário pode ser o primeiro sinal de uma alteração mais importante da linguagem, como o Distúrbio Específico de Linguagem - DEL - (McGregor et al., 2002).

\section{Vocabulário: definição e desenvolvimento}

Em 1985, Genouvier e Peytard explicaram que as palavras que o falante pode usar e compreender constituem seu léxico individual. 
Assim, léxico é o conjunto de todas as palavras que estão à disposição do sujeito, ficando fora dele aquelas com as quais a pessoa não teve contato. Vocabulário é uma amostra do léxico individual, ou seja, o conjunto das palavras que são de fato utilizadas pelo locutor no ato de fala e não nos permite avaliar todo o conhecimento de palavras que o sujeito possui - o vocabulário pode ser avaliado a partir de provas e o léxico não.

Explicando o início do desenvolvimento lexical, Barret (1997) lembrou que esse período mantém inter-relação com as experiências sociointeracionais das crianças e que essas experiências lhes fornecem as formas lexicais convencionais que elas adquirem no início do desenvolvimento; recordou, no entanto, a considerável variação individual nos padrões do crescimento do vocabulário inicial. Explicou, ainda, que as crianças geralmente adquirem suas primeiras palavras entre o $9^{\circ}$ e o $12^{\circ}$ mês de idade, havendo uma explosão no vocabulário dela a partir do momento em que atinge entre 20 e 40 palavras, podendo chegar a 500 palavras entre dois anos e dois anos e meio.

Mencionando outros estudos, Clark (1997) expôs que, no início do desenvolvimento da fala, as crianças falam sobre pessoas e animais, brinquedos e utensílios domésticos, comida e alimentação, rotinas e atividades cotidianas.

\section{Fonologia: definição e desenvolvimento}

Bishop (2000) explicou que as diferentes línguas são compostas por sons (fonemas) distintos. A criança, porém, durante seu desenvolvimento, aprende a ignorar alguns sons e prestar mais atenção àqueles que são utilizados em sua língua materna. É, ainda, durante os primeiros nove meses de vida, que o bebê torna-se sensível apenas aos sons/contrastes portadores de significado em sua língua.

De acordo com Wertzner (2000), no desenvolvimento linguístico da criança, normalmente, observamos processos fonológicos ou simplificações das regras que regem a fonolologia e que podem ser ou não apropriados à faixa etária em que ela se encontra. Wertzner (2003) explicou que as regras fonológicas são aquelas que permitem ao sujeito fazer a distinção entre os diversos fonemas da língua considerando suas particularidades. Por exemplo, em nossa língua, temos fonemas plosivos que devem ser diferenciados dos fricativos, dos líquidos e assim por diante.

\section{Pesquisa realizada em creche municipal}

\subsection{Objetivo}

Esse estudo teve por finalidade principal verificar o efeito da fonologia e do vocabulário na percepção de educadoras sobre a comunicação de seus alunos pré-escolares. 
Os objetivos específicos foram:

- verificar se há diferença entre as faixas etárias quanto ao número de crianças indicadas pelas educadoras como tendo alguma dificuldade de comunicação;

- verificar se as indicações (e as não indicações) das educadoras se confirmam nas provas de fonologia e de vocabulário;

- verificar se há relação da indicação (e da não indicação) com o número de provas em que as crianças falharam;

- verificar a relação da indicação (e da não indicação) com o desempenho das crianças nas provas de vocabulário e de fonologia.

\subsection{Casuística e método}

\subsubsection{Sujeitos}

a) Crianças

Divididas em três grupos de acordo com a faixa etária - G1, G2 e G3 -, conforme pode ser visto na Tabela 1, esta pesquisa conta com a participação de 123 crianças com idade entre 3;0 e 5;11 anos ${ }^{1}$ que frequentam uma creche municipal situada em Santo André, São Paulo.

As crianças participantes do estudo frequentavam três níveis de educação - maternal, jardim I e jardim II. Os critérios de inclusão dos sujeitos na pesquisa foram: idade; assinatura do termo de consentimento, livre e esclarecido, pelos responsáveis; e ausência de síndromes ou outras patologias orgânicas com quadro evidente de alteração de linguagem.

Tabela 1 - Caracterização das crianças

\begin{tabular}{c|c|c} 
Grupos & Distribuição por gênero & Média de idade \\
G1 & 20 meninos & \\
(De 3;0 a 3;11 anos) & 22 meninas & $3 ; 4$ anos (40 meses) \\
G2 & 20 meninos & \\
(De 4;0 a $4 ; 11$ anos) & 20 meninas & $4 ; 3$ anos (51 meses) \\
G3 & 20 meninos & \\
(De 5;0 a 5;11 anos) & 21 meninas & $5 ; 4$ anos (64 meses) \\
\hline
\end{tabular}

b) Educadoras

A pesquisa conta, também, com a participação de sete educadoras responsáveis pelas crianças avaliadas na instituição citada. Elas cursavam ou haviam concluído curso superior em Letras ou Pedagogia.

${ }^{1}$ Indica-se assim a idade em anos e meses. 
Os critérios de inclusão das educadoras como sujeitos de pesquisa foram: ser a responsável pela sala escolhida no período da tarde, aceitar falar sobre as crianças e assinar o termo de consentimento.

\subsubsection{Material}

Foram utilizadas as provas de fonologia (Wertzner, 2000) e as de vocabulário (Befi-Lopes, 2000) do ABFW - Teste de Linguagem Infantil nas Áreas de Fonologia, Vocabulário, Fluência e Pragmática (Andrade et al., 2000).

A aplicação da prova de fonologia consiste na nomeação, pela criança, de 34 figuras e na repetição de 39 vocábulos falados pela avaliadora. Foram analisados os processos fonológicos (as simplificações da fala) em relação à idade da criança e segundo as etapas de aquisição propostas na prova.

A aplicação da prova de vocabulário consiste na nomeação de 118 figuras divididas em 9 campos conceituais (10 figuras de vestuário, 15 de animais, 15 de alimentos, 11 de meios de transporte, 24 de móveis e utensílios, 10 de profissões, 12 de locais, 10 de formas e cores, 11 de brinquedos e instrumentos musicais). Para análise, considerou-se o número total de nomeações esperadas em relação à idade da criança.

\subsubsection{Procedimento}

A avaliadora solicitou à instituição uma lista com os nomes de todas as crianças de cada sala; com essa lista em mãos, perguntou às educadoras quais as crianças que elas julgavam apresentar uma alteração na comunicação e qual, especificamente, era a queixa acerca de cada uma.

Naquelas salas onde duas educadoras eram responsáveis (uma no turno matutino e outra no vespertino), foram consultadas apenas as educadoras do turno vespertino, a fim de se evitar que uma possível discordância entre elas interferisse em nossa pesquisa.

Num segundo momento, todas as crianças da sala, as mencionadas por suas educadoras e também aquelas que não tiveram seus nomes citados, uma de cada vez, foram chamadas a uma sala reservada para a realização de testes de fonologia e vocabulário. No local ficava, na ocasião da coleta, unicamente a pesquisadora e a criança. As duas provas foram gravadas.

Após a coleta de dados, as fitas foram transcritas e os dados foram tabulados e submetidos à análise estatística.

\subsection{Resultados e discussão}

A análise dos resultados obtidos por meio das provas de fonologia e de vocabulário permitiu verificar o desempenho de cada uma das crianças 
avaliadas nesses segmentos da linguagem. Os resultados foram comparados às queixas (ou à ausência de queixa) das educadoras, e essa comparação possibilitou verificar a influência da fonologia e do vocabulário das crianças na percepção das educadoras.

Para cada um dos grupos, serão exibidos os valores obtidos pelas crianças indicadas como tendo alguma dificuldade de comunicação e pelas não indicadas.

\subsubsection{Quanto ao número de crianças indicadas}

Para todos os grupos, foi maior e estatisticamente significante a proporção de crianças não indicadas como tendo alguma dificuldade de comunicação (Tabela 2), o que era esperado, uma vez que a pesquisa foi feita em uma instituição que recebe crianças sem importantes transtornos do desenvolvimento.

Tabela 2 - Número de crianças indicadas e não indicadas pelas educadoras como tendo alguma dificuldade de comunicação

\begin{tabular}{|c|c|c|c|c|}
\hline \multirow{2}{*}{ Grupos } & \multicolumn{2}{|c|}{ Não indicadas } & \multicolumn{2}{c|}{ Indicadas } \\
\cline { 2 - 6 } & $\mathbf{N}^{\mathbf{0}}$ & $\mathbf{\%}$ & $\mathbf{N}^{\mathbf{0}}$ & $\mathbf{\%}$ \\
\hline G1 & 31 & $73,8 \%$ & 11 & $26,2 \%$ \\
\hline G2 & 30 & $75,0 \%$ & 10 & $25,0 \%$ \\
\hline G3 & 34 & $82,9 \%$ & 7 & $17,1 \%$ \\
\hline Total & $\mathbf{9 5}$ & $\mathbf{7 7 , 2 \%}$ & $\mathbf{2 8}$ & $\mathbf{2 2 , 8 \%}$ \\
\hline
\end{tabular}

A ausência de diferença estatística entre cada um dos grupos indicou que, entre as três faixas etárias consideradas, não há uma em que as educadoras estejam mais ou menos preocupadas em relação à comunicação das crianças. Isso pode ser explicado pelas colocações de Martin e Miller (1996) de que as professoras, assim como os pais, também tendem a comparar as crianças entre si, e de Lahey (1990) de que a comparação entre membros de uma mesma idade cronológica é um dos parâmetros mais utilizados pelos profissionais de avaliação. Portanto, se as crianças consideradas como tendo alguma dificuldade de comunicação, teriam sido assim consideradas em razão da comparação com outras da mesma idade, não era esperado que um dos grupos tivesse um maior número de indicações.

\subsubsection{Quanto à confirmação da indicação e da não indicação das educadoras pelas provas de fonologia e de vocabulário}

Com o objetivo de investigar se as indicações das educadoras se confirmariam nas provas de fonologia e de vocabulário, verificou-se o número de crianças indicadas de cada grupo que falharam em, pelo menos, uma das provas (Tabela 3). 
Tabela 3 - Proporção de crianças que falharam e que não falharam em alguma das provas

\begin{tabular}{|c|c|c|c|c|c|c|c|c|c|c|c|c|}
\hline & \multicolumn{4}{|c|}{ G1 } & \multicolumn{4}{|c|}{ G2 } & \multicolumn{4}{|c|}{ G3 } \\
\hline & \multicolumn{2}{|c|}{ Indicadas } & \multicolumn{2}{|c|}{$\begin{array}{c}\text { Não } \\
\text { indicadas }\end{array}$} & \multicolumn{2}{|c|}{ Indicadas } & \multicolumn{2}{|c|}{$\begin{array}{c}\text { Não } \\
\text { indicadas }\end{array}$} & \multicolumn{2}{|c|}{ Indicadas } & \multicolumn{2}{|c|}{$\begin{array}{c}\text { Não } \\
\text { indicadas }\end{array}$} \\
\hline & $\mathbf{N}^{\circ}$ & $\%$ & $\mathbf{N}^{\circ}$ & $\%$ & $\mathbf{N}^{\circ}$ & $\%$ & $\mathbf{N}^{\mathbf{o}}$ & $\%$ & $\mathbf{N}^{\circ}$ & $\%$ & $\mathbf{N}^{\circ}$ & $\%$ \\
\hline Falha & 7 & $63,6 \%$ & 11 & $35,5 \%$ & 9 & $90,0 \%$ & 7 & $23,3 \%$ & 5 & $71,4 \%$ & 10 & $29,4 \%$ \\
\hline $\begin{array}{c}\text { Não } \\
\text { falharam }\end{array}$ & 4 & $36,4 \%$ & 20 & $64,5 \%$ & 1 & $10,0 \%$ & 23 & $76,7 \%$ & 2 & $28,6 \%$ & 24 & $70,6 \%$ \\
\hline
\end{tabular}

Entre as crianças indicadas pelas educadoras como tendo alguma dificuldade de comunicação, confirmamos que, no G2 e no G3, a maior parte delas falhou em alguma das provas. No G1, apesar de o número de crianças que falharam ser maior, não há diferença estatística. Mas se, de uma maneira geral, a maior parte das crianças indicadas falhou em alguma das provas, isso significa que as habilidades de fonologia e vocabulário podem nos ajudar a compreender o que as educadoras chamam de dificuldade de comunicação.

Avaliando agora os resultados obtidos pelas crianças que não foram indicadas, ou seja, com uma comunicação que não causa estranhamento nas educadoras, encontramos uma proporção maior e estatisticamente significante de crianças que não falharam em nenhuma das provas - o que pode confirmar a não indicação. No entanto, quando consideramos todas as que falharam em alguma das provas, encontramos um número considerável de crianças que não foram indicadas pelas educadoras: para o G3, entre as que falharam, chega a ser estatisticamente maior o número de crianças não indicadas em relação às indicadas.

Esses últimos resultados mostram que as razões pelas quais crianças não indicadas falharam em uma ou nas duas provas não serviram para as educadoras como sinalizadores de uma dificuldade de comunicação. O que pode justificar o fato de essas crianças não terem despertado nas educadoras uma preocupação? Provavelmente as crianças de quatro ou cinco anos que não têm sua comunicação questionada por suas educadoras já devem ter superado as principais etapas do desenvolvimento fonológico pertinentes à sua idade (Ingran, 1976, Lowe, 1996, Wertzner, 2000) e, também, atingido um nível de conhecimento de palavras que lhes dá condições de manterem uma efetividade comunicativa (Befi-Lopes, 1997, Clark, 1997).

Mas, na tentativa de compreender esses dados, apresentamos a seguir uma análise quanto ao número de provas nas quais as crianças falharam: uma (vocabulário ou fonologia) ou duas (vocabulário e fonologia). 


\subsubsection{Quanto à relação da indicação e da não indicação com o número de provas nas quais a criança falhou}

Começando agora pelas crianças consideradas como tendo um comportamento comunicativo dentro das normas, temos que, para os três grupos, foi maior e estatisticamente significante o número de crianças que falharam em apenas uma das provas (Tabela 4). Esse resultado indica uma tendência, por parte das educadoras, de não caracterizarem como tendo uma dificuldade aquelas que falharam apenas em vocabulário ou em fonologia - o que pode ajudar na compreensão dos resultados discutidos anteriormente.

Considerando as crianças indicadas pelas educadoras, encontramos um resultado particular para cada um dos grupos: no G1, houve uma proporção maior e estatisticamente significante de crianças indicadas que falharam nas duas provas (fonologia e vocabulário); no G2, não houve diferença entre aquelas que falharam em uma e nas duas provas; e, por fim, no G3, as crianças indicadas falharam expressivamente em uma prova apenas.

Tabela 4 - Proporção de crianças que falharam em uma ou em duas das provas

\begin{tabular}{|c|c|c|c|c|c|c|c|c|c|c|c|c|}
\hline & \multicolumn{4}{|c|}{ G1 } & \multicolumn{4}{|c|}{ G2 } & \multicolumn{4}{|c|}{ G3 } \\
\hline & \multicolumn{2}{|c|}{ Indicadas } & \multicolumn{2}{|c|}{$\begin{array}{c}\text { Não } \\
\text { indicadas }\end{array}$} & \multicolumn{2}{|c|}{ Indicadas } & \multicolumn{2}{|c|}{$\begin{array}{c}\text { Não } \\
\text { indicadas }\end{array}$} & \multicolumn{2}{|c|}{ Indicadas } & \multicolumn{2}{|c|}{$\begin{array}{c}\text { Não } \\
\text { indicadas }\end{array}$} \\
\hline & $\mathbf{N}^{\circ}$ & $\%$ & $\mathbf{N}^{\circ}$ & $\%$ & $\mathbf{N}^{\mathbf{0}}$ & $\%$ & $\mathbf{N}^{\circ}$ & $\%$ & $\mathbf{N}^{\mathbf{0}}$ & $\%$ & $\mathbf{N}^{\circ}$ & $\%$ \\
\hline $\begin{array}{c}\text { Duas } \\
\text { provas }\end{array}$ & 6 & $85,7 \%$ & 1 & $9,1 \%$ & 4 & $44,4 \%$ & 1 & $14,3 \%$ & 0 & $0,0 \%$ & 1 & $10,0 \%$ \\
\hline $\begin{array}{c}\text { Uma } \\
\text { prova }\end{array}$ & 1 & $14,3 \%$ & 10 & $90,9 \%$ & 5 & $55,6 \%$ & 6 & $85,7 \%$ & 5 & $100,0 \%$ & 9 & $90,0 \%$ \\
\hline
\end{tabular}

Vimos que as crianças menores são caracterizadas como tendo dificuldade de comunicação quando elas apresentam uma manifestação mais ampla (falha nas duas provas) e que, à medida que a idade avança, torna-se mais fácil a identificação da falha ou do atraso pelas educadoras, levando-as a indicarem crianças de cinco anos, mesmo quando há falha em apenas uma das provas.

\subsubsection{Quanto à relação da indicação e da não indicação com o desempenho da criança nas provas de vocabulário e de fonologia}

Analisando o desempenho das crianças em cada uma das provas, observamos que as indicadas do G1 falharam predominantemente nas duas provas; já as não indicadas falharam em fonologia. 
Os dados da Tabela 5 nos levam a concluir que as crianças de três anos de idade chamam a atenção da educadora em relação ao seu comportamento comunicativo, principalmente quando apresentam um atraso mais abrangente (envolvendo mais de um aspecto da linguagem). Por outro lado, aquelas que falharam em apenas um dos aspectos avaliados não foram indicadas como tendo uma dificuldade de comunicação. No entanto, deve-se dar importância ao fato de tantas falhas em fonologia terem sido toleradas e consideradas normais.

Tabela 5 - Proporção de crianças que falharam em cada uma das provas ou nas duas

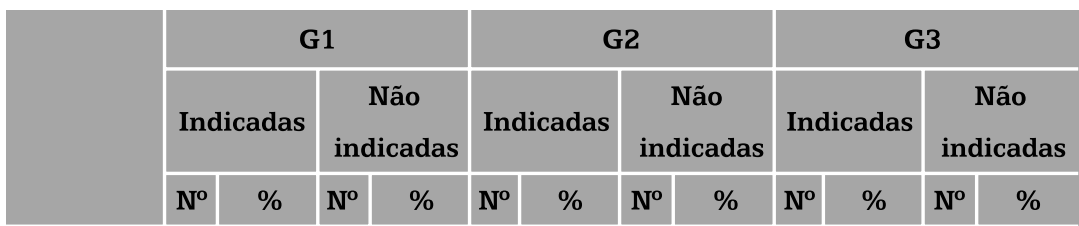

$\begin{array}{lllllllllllll}\text { Fonologia } & 1 & 14,3 \% & 8 & 72,7 \% & 4 & 44,4 \% & 2 & 28,6 \% & 3 & 60,0 \% & 3 & 30,0 \%\end{array}$

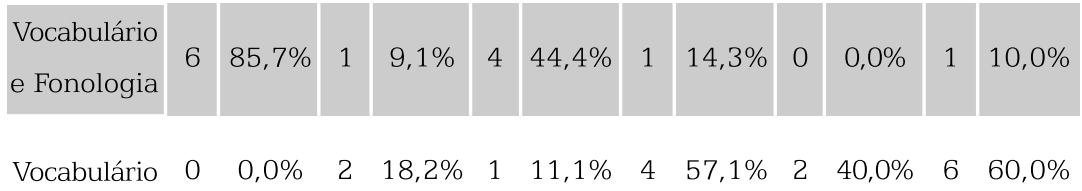

A "dificuldade encontrada em perceber o que é normal e o que é alteração, principalmente em crianças mais jovens" (Befi-Lopes, 2003), pode justificar os dados obtidos. Crenças como "nada pode ser feito antes dos quatro anos" (Copper; Moodley; Reynell, 1989) também podem contribuir para que as crianças menores estejam isentas de uma escuta mais avaliadora. Mas o fato é que nem tudo é permitido a uma criança de três anos e que, a essa idade, certas etapas do desenvolvimento fonológico já devem ter sido superadas, conforme propôs Wertzner (2000). E não se deve esquecer que as habilidades fonológicas das crianças pequenas são importantes para prevermos como se dará sua performance em habilidades posteriores do desenvolvimento (Hodson, 1994) e, portanto, merecem atenção.

No G2, verifica-se que as crianças indicadas pelas educadoras falharam ou nas duas provas ou somente em fonologia. Isso aponta que, com o aumento da idade, aumentou também a preocupação sobre como as crianças pronunciam os sons da língua e, portanto, houve uma maior ocorrência de falha na prova de fonologia entre as indicadas. No G3, as crianças indicadas falharam em fonologia e em vocabulário.

Um dado que merece destaque, porém, é o de que tanto para as crianças não indicadas do G2 quanto do G3 (confirmado estatisticamente), podemos observar um predomínio de crianças que falharam na prova de vocabulário. E se as educadoras deixaram de indicar essas crianças que 
falharam somente em vocabulário, é porque esse aspecto não é frequentemente notado por elas. É possível, então, que as crianças indicadas que falharam em vocabulário tenham recebido a indicação por outras razões.

Sabemos que existe maior chance de uma falha no vocabulário passar despercebida do que uma de fonologia. Isso ocorre porque o desempenho da criança em uma prova de nomeação pode ser bastante diferente do seu desempenho em situações espontâneas, ou seja, ela pode ficar inibida na situação de teste ou estar numa fase primitiva de associação do rótulo ao objeto - e somente ser capaz de nomear em situações contextualizadas (Cooper; Moodley; Reynell, 1989). Também é possível que as educadoras julguem que o fato de a criança compreender a palavra signifique que ela saiba a palavra; no entanto, Harris et al. (1995) colocaram compreensão e produção da palavra como duas etapas que ocorrem, inclusive, em tempos diferentes.

Mesmo considerando as afirmações anteriores, é preocupante que tantas crianças que falharam na prova de vocabulário não tenham sido indicadas como tendo dificuldade de comunicação. Vale ressaltar a importância de considerarmos o quanto ela é capaz de produzir palavras, pois o vocabulário é fundamental para etapas posteriores do desenvolvimento infantil (Cunha; Castro, 1978, Scheuer; Befi-Lopes; Wertzner, 2003, Stahl, 2003).

\section{Conclusão}

A fonoaudiologia, ciência que estuda a comunicação humana, nasceu da área da educação. Desde então, ela cresce e se aperfeiçoa, mas jamais negligenciou o fundamental papel dos profissionais da educação no que se refere ao diagnóstico e ao tratamento dos transtornos da linguagem. Quem não conhece uma criança que foi inserida no ambiente escolar para que obtivesse meios de melhorar seu desenvolvimento linguístico?

Nossa prática profissional evidencia haver grande interesse, por parte das duas áreas, no estabelecimento de trocas de informações que possam favorecer o público infantil. No entanto, por questões diversas que passam pela ética profissional - que impede o fonoaudiólogo de fazer atendimento clínico nos ambientes de ensino normal - e pela saúde pública brasileira - que oferece um número insuficiente de fonoaudiólogos, o que desestimula o encaminhamento de crianças por parte dos educadores -, esse diálogo acaba sendo afetado.

Quem perde é o aluno que, muitas vezes, não precisaria se tornar um paciente, se seu educador e seu fonoaudiólogo tivessem meios de dialogar sobre assuntos que concernem ao desenvolvimento linguístico infantil. O que cada um considera normal? O que cada um considera alteração? Como cada um considera a comunicação de uma mesma criança, e como as práticas de um podem auxiliar no bom desenvolvimento da prática profissional do outro? 
Para o estudo aqui apresentado, as crianças não passaram por avaliação fonoaudiológica e, portanto, não foi feito diagnóstico de linguagem. O objetivo geral dessa pesquisa foi verificar o efeito de dois segmentos da linguagem humana obrigatoriamente considerados na avaliação fonoaudiológica - o vocabulário e a fonologia - na percepção de educadoras acerca da comunicação de seus alunos pré-escolares.

Os dois aspectos avaliados são extremamente importantes para toda a linguagem, e o prejuízo em um deles pode deixar marcas que acompanham todo o desenvolvimento do indivíduo.

Por meio das análises dos resultados, pudemos perceber que a maneira como fonologia e vocabulário interferiram na percepção das educadoras variou de acordo com a idade das crianças. Parece haver uma tendência de se tolerar as falhas de produção do som da língua, quando realizadas por crianças de três anos, mesmo que essas já devam ter cumprido e superado determinadas etapas de aquisição. Ao contrário, para as mais velhas, principalmente as de cinco anos, a maneira como produzem a palavra é valorizada em detrimento da quantidade de palavras produzidas.

Nossa pesquisa vem reforçar a necessidade de uma (re)aproximação da fonoaudiologia e a educação.

\section{Referências bibliográficas}

ALVES, R. C. D. Fonologia e vocabulário na percepção de educadoras sobre comunicação de pré-escolares. 2005. Dissertação (Mestrado em Linguística) - Universidade de São Paulo (USP), 2005

BARRET, M. Desenvolvimento lexical inicial. In: FLETCHER, P.; MacWHINNEY, B. Compêndio da linguagem da criança. Porto Alegre: Artes Médicas, 1997. Cap. 13, p. 299-321.

BEFI-LOPES, D. M. Aspectos da competência e do desenvolvimento lexicais em crianças entre 4:0 e 6:6 anos, com padrões de desenvolvimento normal de linguagem e com alterações articulatórias. 1997. Tese (Doutorado em Linguística) -Universidade de São Paulo, 1997.

Vocabulário. In: ANDRADE, C. R. F.; BEFI-LOPES, D. M.; FERNANDES, F. D. M.; WERTZNER, H. F. ABFW: teste de linguagem infantil nas áreas de fonologia, vocabulário, fluência e pragmática. São Paulo: Pró-Fono, 2000. p. 41-47.

Prova de verificação do vocabulário: aspectos da efetividade como instrumento diagnóstico. 2002. Tese (Livre-Docência em Fonoaudiologia) - Faculdade de Medicina da Universidade de São Paulo (USP), 2002. 
BEFI-LOPES, D M. Alterações do desenvolvimento da linguagem.

In: LIMONGI, S. C. O. Linguagem: desenvolvimento normal, alterações e distúrbios. São Paulo: Guanabara Koogan, 2003. Cap. 2, p. 19-32. (Série Fonoaudiologia: informação para a formação).

BEFI-LOPES, D. M.; GALEA, D. E. S. Análise do desempenho lexical em crianças com alterações no desenvolvimento da linguagem. Pró-Fono Revista de Atualização Científica, Barueri, v. 12, n. 2, p. 31-38, set. 2000 .

BEFI-LOPES, D. M.; RODRIGUES, A. Verificação do vocabulário nas alterações de desenvolvimento de linguagem. Jornal Brasileiro de Fonoaudiologia, Curitiba, v. 2, n. 8, p. 183-190 jul./set. 2001.

BENEDICT, H. Early lexical development: comprehension and production. Journal of child language, v. 6, n. 1, p. 183-200, 1979.

BERBERIAN, A. P. Fonoaudiologia e educação: um encontro histórico. 2. ed. São Paulo: Plexus, 2000.

BISHOP, D. V. M.; ADAMS, C. A prospective study of the relationship between specific impairment, phonological disorders and reading retardation. Journal of Child Psychology and Psychiatry, v. 31, p. 1027-1050, 1990.

BISHOP, D. V. M. How does the brain learn language? Insights from the study of children with and without language impairment. Developmental Medicine G Child Neurology, v. 42, p. 133-142, 2000.

CLARK, E. V. Desenvolvimento lexical tardio e formação de palavras. In: FLETCHER, P.; MACWHINNEY, B. Compêndio da linguagem da criança. Porto Alegre: Artes Médicas, 1997. Cap. 13, p. 299-321.

COOPER, J.; MOODLEY, M.; REYNELL, J. Helping language development: a developmental programme for children with early language handicaps. London: Edward Arnold, 1989.

CUNHA, N. S.; CASTRO, I. C. SIDAPE: Sistema de Estimulação Pré-Escolar. São Paulo: Criação Editorial, 1978.

EISENSON, J. Language and speech disorders in children. New York: Pergamon Books, 1986.

GENOUVIER, E.; PEYTARD, J. Linguística e ensino do Português.

Coimbra: Almedina, 1985. 
HARRIS, M. A. K; YEELES, J. C.; OAKLEY, Y. Symmetries and asymmetries en early lexical comprehension and production. Journal of Child Language, v. 22, p. 1-18, 1995.

HODSON, B. W. Helping individuals become intelligible, literate and articulate: the role of phonology. Topics in Language Disorders, v. 14, n. 2, p. 1-16, feb. 1994.

INGRAN, D. Aspects of phonological acquisition. In: Phonological disability in children. London: Guildford, 1976. Cap. 2, p. 10-51.

LAHEY, M. Who shall be called language disordered? Some reflections and one perspective. Journal of Speech and Hearing Disorders, v. 55, p. 612-620, nov. 1990.

LOWE, R. J. Fonologia: avaliação e intervenção - aplicações na patologia da fala. Porto Alegre: Artes Médicas, 1996.

MARTIN, D.; MILLER, C. Speech and language difficulties in the classroom. London: David Fulton, 1996.

McGREGOR, K. K. et al. Semantic representation and naming in children with specific language impairment. Journal of Speech, Language and Hearing Research, v. 45, p. 998-1014, oct. 2002.

REED, V.A. Association between phonology and other language components in children's communicate performance: clinical implications. Australian Journal of Human Communicate Disorders, v. 20, p. 75-87, dec. 1992.

SCHEUER, C.; BEFI-LOPES, D. M.; WERTZNER, H. F. Desenvolvimento da linguagem: uma introdução. In: LIMONGI, S. C. O. Linguagem: desenvolvimento normal, alterações e distúrbios. São Paulo: Guanabara Koogan, 2003. Cap. 1, p.1-18. (Série Fonoaudiologia: informação para a formação).

SNOWLING, M. Dislexia desenvolvimental: uma introdução e visão teórica geral. In: SNOWLING, M.; STACKHOUSE, J. Dislexia, fala e linguagem: um manual do profissional. Porto Alegre: Artmed, 2004. Cap. 1, p. 11-21.

SNOWLING, M.; STACKOUSE, J. Dislexia, fala e linguagem: um manual do profissional. Porto Alegre: Artmed, 2004.

STACKHOUSE, J. Fala, ortografia e leitura: quem está em risco e por quê? In: SNOWLING, M.; STACKHOUSE, J. Dislexia, fala e linguagem: um manual do profissional. Porto Alegre: Artmed, 2004. Cap. 2, p. 22-33. 
STAHL, S.A. Vocabulary and readability: how knowing word meanings affects comprehension. Topic in Language Disorders, v. 23, n. 3, p. 241-247, july/sept. 2003.

WERTZNER, H. F. Articulação: aquisição do sistema fonológico dos três aos sete anos. 1992. Tese (Doutorado em Linguística) - Universidade de São Paulo (USP), 1992.

Estudo da aquisição do sistema fonológico em crianças de três a sete anos. Pró-Fono Revista de Atualização Científica, Barueri, SP, v.7, n.1, p.21-26, 1995.

Fonologia. In: ANDRADE, C. R. F.; BEFI-LOPES, D. M.; FERNANDES, D. M.; WERTZNER, H. F. ABFW: teste de linguagem infantil nas áreas de fonologia, vocabulário, fluência e pragmática. São Paulo: Pró-Fono: 2000. Cap. 1, p. 5-16.

Distúrbio Fonológico. In: LIMONGI, S. C. O. Linguagem: desenvolvimento normal, alterações e distúrbios. São Paulo: Guanabara Koogan, 2003, cap.3, p.33-47. (Fonoaudiologia informação para a formação).

Rita de Cássia Alves Limissuri, mestre em Semiótica e Linguística Geral pela Universidade de São Paulo, é especializanda em Psicolinguística no Laboratoire de Sciences Cognitives et Psycholinguistique da École Normale Supérieure, de Paris, França, e fonoaudióloga do Centro de Reabilitação Policlin, de São José dos Campos, São Paulo. Publicou artigos em periódicos e anais.

rita_dias_alves@hotmail.com

Débora Maria Befi-Lopes, livre-docente em Fonoaudiologia pela Faculdade de Medicina da Universidade de São Paulo (FMUSP), é professora associada do curso de Fonoaudiologia da Faculdade de Medicina dessa universidade. Organizou o Tratado de Fonoaudiologia, publicado pela editora Roca, em 2004. Escreve para revistas especializadas.

dmblopes@usp.br.

Recebido em 11 de setembro de 2008.

Aprovado em 17 de abril de 2009. 